\title{
Cellular pharmacokinetics and intracellular activity of the bacterial fatty acid synthesis inhibitor, afabicin desphosphono against different resistance phenotypes of Staphylococcus aureus in models of cultured phagocytic cells
}

\author{
Frédéric Peyrusson ${ }^{\mathrm{a}}$, Astrid Van Wessem ${ }^{\mathrm{a}, 1}$, Guennaëlle Dieppois ${ }^{\mathrm{b}}$, Françoise Van \\ Bambeke ${ }^{a}$, Paul M. Tulkens ${ }^{\text {a,* }}$ \\ a Pharmacologie cellulaire et moléculaire, Louvain Drug Research Institute, Université catholique de Louvain (UCLouvain), avenue E. Mounier 73 Bte \\ B1.73.05, B-1200 Bruxelles, Belgium \\ ${ }^{\mathrm{b}}$ Debiopharm International SA, Chemin Messidor 5, CH-1006 Lausanne, Switzerland
}

\section{A R T I C L E I N F O}

\section{Article history:}

Received 15 August 2019

Accepted 13 November 2019

Editor: H. Derendorf

Keywords:

Debio-1452

Fatty acid synthesis inhibitor

Staphylococcus aureus

THP-1 monocytes

J774 macrophages

Intracellular activity

Cell fractionation

Accumulation

\begin{abstract}
A B S T R A C T
Antibiotics with new modes of action that are active against intracellular forms of Staphylococcus aureus are sorely needed to fight recalcitrant infections caused by this bacterium. Afabicin desphosphono (Debio 1452, the active form of afabicin [Debio 1450]) is an inhibitor of FabI enoyl-Acyl carrier protein reductase and has specific and extremely potent activity against Staphylococci, including strains resistant to current antistaphylococcal agents. Using mouse J774 macrophages and human THP-1 monocytes, we showed that afabicin desphosphono: (i) accumulates rapidly in cells, reaching stable cellular-to-extracellular concentration ratios of about 30; (ii) is recovered entirely and free in the cell-soluble fraction (no evidence of stable association with proteins or other macromolecules). Afabicin desphosphono caused a maximum cfu decrease of about $2.5 \log _{10}$ after incubation in broth for $30 \mathrm{~h}$, including against strains resistant to vancomycin, daptomycin, and/or linezolid. Using a pharmacodynamic model of infected THP-1 monocytes (30 h of incubation post-phagocytosis), we showed that afabicin desphosphono is bacteriostatic (maximum cfu decrease: 0.56 to $0.73 \log _{10}$ ) towards all strains tested, a behaviour shared with the comparators (vancomycin, daptomycin, and linezolid) when tested against susceptible strains. We conclude that afabicin desphosphono has a similar potential as vancomycin, daptomycin or linezolid to control the intracellular growth and survival of phagocytized $S$. aureus and remains fully active against strains resistant to these comparators.
\end{abstract}

(c) 2019 Elsevier B.V. and International Society of Chemotherapy. All rights reserved.

\section{Introduction}

Staphylococcus aureus represents a major and recurrent challenge to clinicians due to the combination of bacterial and host factors [1] and is considered by the World Health Organization to be a high priority pathogen for development of novel therapies [2]. S. aureus readily adapts to changing environments and acquires antibiotic-resistance genes through several different mechanisms [3]; this has led to an almost constant increase and broadening of resistance that today affects most (if not all) the major classes of clinically-approved antibiotics, including glycopeptides,

\footnotetext{
* Corresponding author: Bte B1.73.05 avenue E. Mounier, B-1200 Bruxelles, Belgium, Tel.: + 3227647341 .

E-mail address: tulkens@facm.ucl.ac.be (P.M. Tulkens).

1 Present affiliation: Promethera Biosciences, Wavre, Belgium
}

fluoroquinolones and oxazolidinones [4,5]. S. aureus can survive and thrive in professional and non-professional phagocytes, where it evades immune defences and against which antibiotic action is severely limited compared with extracellular forms [6-8]. In this context, while discovery and development of new chemical or biological entities targeting unexploited but essential targets in $S$. aureus is of prime importance to evade existing mechanisms of resistance [9], their activity in difficult environments and intracellular niches must also be carefully assessed to ensure their efficacy against difficult-to-treat $S$. aureus infections.

The present study focuses on the activity of the first-in-class FabI enoyl-Acyl carrier protein reductase inhibitor, afabicin desphosphono (Debio 1452; first described as API 1252 [10] or AFN-1252 $[11,12]$; see Fig. 1 for structure and main biophysical properties) on intracellular S. aureus. Afabicin desphosphono is the active moiety of afabicin (Debio 1450), which has completed Phase II in acute bacterial skin and skin structure infections and is presently being 


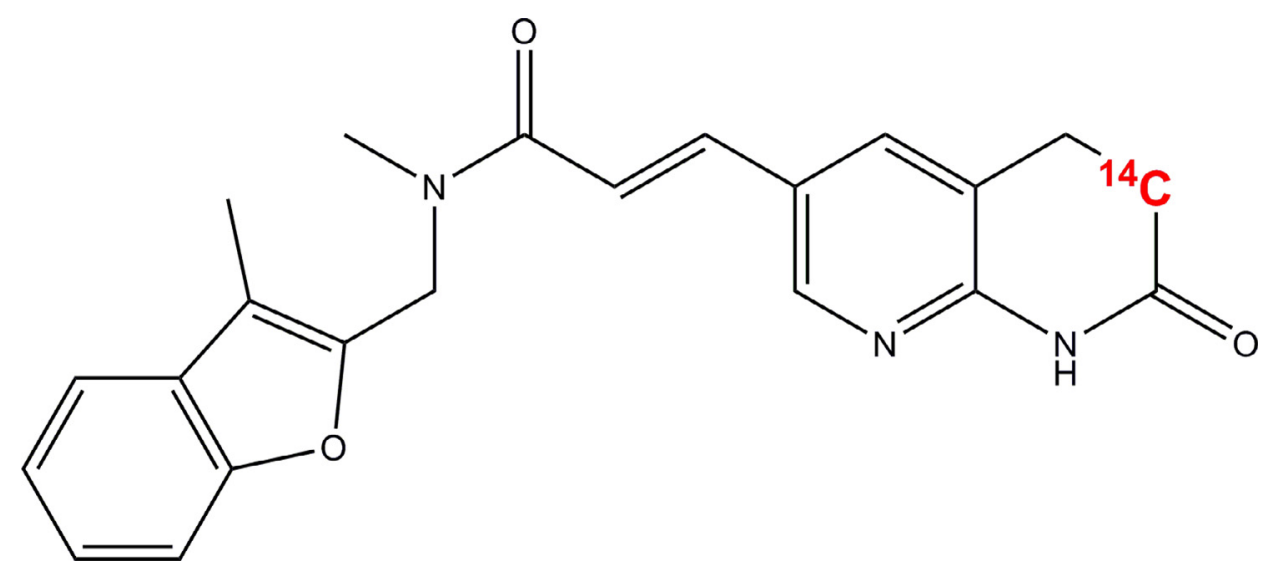

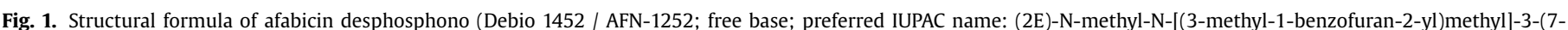

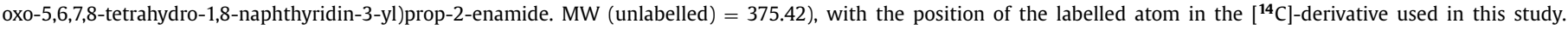

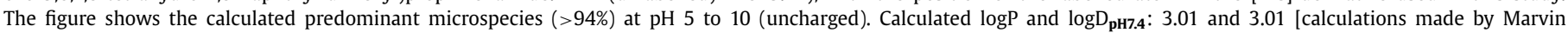
Sketch version 18.25 (academic license), Chemaxon (Budapest, Hungary; https://chemaxon.com/)].

investigated for the treatment of bone and joint infections [13]. Of note, afabicin desphosphono displays a selective and highly potent antibacterial activity against Staphylococci, with minimum inhibitory concentrations (MICs) typically $\leq 0.015 \mathrm{mg} / \mathrm{L}$ against contemporary clinical isolates $[11,14]$, and little to no activity against other species, hence causing minimal disturbance to the gut bacterial abundance and composition [15]. Afabicin desphosphono has very limited water solubility, high permeability across the mouse intestinal wall and good distribution in skin structures [16], indicating possible penetration into eukaryotic cells.

In this study, the cellular pharmacokinetics (uptake and release) and subcellular disposition of afabicin desphosphono were examined in cultured mouse macrophages and human monocytes using established techniques developed for other antibiotics [17-19]. Intracellular activity of afabicin desphosphono against phagocytized $S$. aureus with different resistance phenotypes was compared with that of linezolid, daptomycin and vancomycin using a validated pharmacodynamic model of infected human monocytes [20].

\section{Materials and Methods}

\subsection{Materials}

Afabicin desphosphono was provided by Debiopharm International (Lausanne, Switzerland) and routinely prepared in dimethyl sulfoxide (DMSO) at concentrations 100-fold higher than the final desired concentrations, then diluted 100-fold in the desired medium. $\left[{ }^{14}\right] \mathrm{C}$-labelled afabicin desphosphono (4.77 MBq/mg; label in position 25; see Fig. 1) was provided by Almac Sciences (Craigavon, UK) on order of Debiopharm, and diluted with unlabelled afabicin desphosphono to obtain the desired specific activity. The following antibiotics were obtained as microbiological standards: clarithromycin, from SMB Galephar (Marche-enFamenne, Belgium); and oxacillin monohydrate and gentamicin sulphate, from Sigma-Aldrich (St. Louis, MO). The other antibiotics were obtained as the corresponding branded products registered for human parenteral use in Belgium and complying with the provisions of the European Pharmacopoeia (vancomycin as Vancomycine Mylan ${ }^{\circledR}$ [Mylan Inc., Canonsburg, PA]; daptomycin as Cubicin ${ }^{\circledR}$ [Novartis, Horsham, United Kingdom]; and linezolid as Zyvoxid® [Pfizer Inc., New York, NY]). Human serum for opsonisation was obtained from Biowest SAS (Nuaillé, France), and cell culture media and sera from Gibco - Thermo Fisher Scientific (Waltham, MA). Unless stated otherwise, all other products were obtained from Sigma-Aldrich or Merck KGaA (Darmstadt, Germany).

\subsection{Cells}

Mouse J774 macrophages, originally derived from a mouse reticulosarcoma and obtained from Sandoz Forschung Laboratories (Vienna, Austria), were maintained as monolayers and used at confluency. Human THP-1 monocytes, originally derived from a patient with acute monocytic leukaemia and obtained from the American Culture Collection (ATCC, Manassas, VA) as clone ATCC TIB-202, were propagated in suspension and used at a typical concentration of $0.5 \times 10^{6}$ cells $/ \mathrm{mL}$. Both cell lines were grown in RPMI 1640 medium supplemented with $10 \%$ foetal bovine serum and $2 \mathrm{mM}$ glutamine (Gibco) in an atmosphere of $95 \%$ air- $5 \% \mathrm{CO}_{2}$ at $37^{\circ} \mathrm{C}$ as described previously $[21,22]$.

\subsection{Cellular pharmacokinetic and cell fractionation studies}

For drug uptake and release studies, J774 macrophages monolayers were quickly washed free of culture medium using phosphate-buffered saline (PBS) and then treated as described previously [23]. For cell fractionation studies, J774 macrophages monolayers were washed with PBS (twice) and then with 0.25 M sucrose-1 mM EDTA-3mM Tris-HCl pH 7.4 (sucrose-EDTA-Tris) twice and collected by scraping with a Teflon ${ }^{\circledR}$ policeman in the same medium. THP-1 monocytes were collected by centrifugation, washed twice in PBS and twice in sucrose-EDTA-Tris and resuspended in the same medium. Cells were then homogenized by 5 to 10 passages of the "tight" pestle of an all-glass Dounce tissue grinder (Thomas Scientific, Swedesboro, NJ) with microscopic (phase contrast) checking for cell disruption. The resulting homogenate was subjected to differential centrifugation as follows: (i) an $\mathrm{N}$ fraction (containing unbroken cells and nuclei) was prepared by low-speed centrifugation (1600 revolutions per min [rpm], $10 \mathrm{~min}, \mathrm{GH}-3.8 \mathrm{~A}$ swinging buckets rotor, Allegra centrifuge $\mathrm{X}-12 \mathrm{R}$, Beckman-Coulter Life Sciences, Indianapolis, IN) followed by one washing of the pellet with combination of the two supernatants; (ii) the combined supernatants (fraction E [cytoplasmic extract]) were then subjected to high-speed centrifugation (30 000 rpm, 30 min, rotor Ti-50, Beckman-Optima LE-80K ultracentrifuge, Beckman-Coulter) to yield an MLP fraction (containing the bulk of the subcellular organelles and membranes) and an S fraction (soluble material). Isopycnic centrifugation of the whole cytoplasmic extract (fraction E) was made by depositing a sample on top of a linear sucrose gradient (density limits: 1.10 to 1.24 ) resting on a cushion of sucrose of density 1.34, and centrifuging it at $35000 \mathrm{rpm}$ for $3 \mathrm{~h}$ in a rotor SW $40 \mathrm{Ti}$ (Beckman). In one experiment, the S fraction was deposited on top of the sucrose gradient and cen- 
Table 1

Strains used in the study with origin and minimum inhibitory concentration (MIC) in broth

\begin{tabular}{|c|c|c|c|c|c|c|c|c|}
\hline Strain & Origin & \multicolumn{7}{|l|}{$\operatorname{MIC}(\mathrm{mg} / \mathrm{L})^{\mathrm{a}}$} \\
\hline ATCC 25923 & Laboratory standard ${ }^{\mathrm{b}}$ & $0.003906^{*}$ & 0.25 & 0.25 & 1 & 1 & $4^{*}$ & $0.125^{*}$ \\
\hline SA 040 & Clinical isolate $^{\mathrm{d}}$ & $0.003906^{*}$ & 0.25 & 0.25 & $1^{*}$ & $2^{*}$ & 4 & 0.0625 \\
\hline SA $040 \mathrm{LZD}^{\mathrm{R}}$ & Mutant from clinical isolate ${ }^{\mathrm{d}}$ & $0.003906^{*}$ & 0.25 & 0.25 & $2^{*}$ & 2 & 16 & 0.125 \\
\hline SA 312 & Clinical isolate $^{\mathrm{d}}$ & $0.003906^{*}$ & 64 & 64 & $1^{*}$ & $\mathbf{2}^{*}$ & $4^{*}$ & 0.0625 \\
\hline VUB 09 & Clinical isolate ${ }^{g}$ & 0.001953 & 64 & $>256$ & $1^{*}$ & 2 & 2 & 4 \\
\hline MU 50 & Deposited clinical isolate $^{\mathrm{h}}$ & $0.003906^{*}$ & $>256$ & $>256$ & 8 & 8 & 1 & $4^{*}$ \\
\hline
\end{tabular}

a Abbreviations: OXA, oxacillin; CLR, clarithromycin; VAN, vancomycin; DAP, daptomycin; LZD, linezolid; MXF, moxifloxacin. All assays were conducted in triplicate and/or are from previous publications (see [24,25]); values with an asterisk denote assays where a 1 log ${ }_{2}$ lower value was occasionally observed. Figures in bold indicate values greater than the EUCAST resistant ("R") clinical breakpoint values for Staphylococcus spp. (in mg/L): OXA: >2; CLR: $>2$; VAN: $>2$; DAP: $>1$; LZD: $>4$; MXF: $>0.25$; see: The European Committee on Antimicrobial Susceptibility Testing: Breakpoint tables for interpretation of MICs and zone diameters, version 9.0, valid from 2019-01-01http://www.eucast.org).

${ }^{\mathrm{b}}$ Laboratory Standard (American Tissue Culture Collection [ATCC], Manassas, VA).

c Laboratory standard (ATCC, Manassas, VA) and EUCAST quality control Staphylococcus aureus.

d Strain from P. Appelbaum, Hershey Medical Center, Hershey, PA. ${ }^{e}$ Respiratory tract infection; strain from P. Appelbaum, Hershey Medical Center, Hershey, PA.

f Dialysis-associated peritonitis; strain from M.J. Ferraro, Massachusetts General Hospital, Boston, MA; obtained from the Network on Antimicrobial Resistance in Staphylococcus aureus (NARSA; presently BEI Resources, Manassas, VA).

$g$ Wound infection; strain from D. Pierard, Universitair Ziekenhuis Brussel, Brussels, Belgium.

h Wound infection; strain from K. Hiramatsu, Department of Bacteriology, Juntendo University, Tokyo, Japan; also known as NRS1; deposited as Staphylococcus aureus Rosenbach and commercially available as strain ATCC 700699 (ATCC, Manassas, VA).

trifuged for $24 \mathrm{~h}$ at $35000 \mathrm{rpm}$ also in rotor SW 40 Ti. After centrifugation, the content of the tube was collected in 12 to 16 fractions of roughly equal volume. All fractions were assayed for radioactivity (when using $\left[{ }^{14} \mathrm{C}\right]$-labelled afabicin desphosphono), proteins and marker enzymes (lactate dehydrogenase [LDH; cytosol]; N-acetyl- $\beta$-hexosaminidase [NAB; lysosomes], and cytochrome $c$-oxidase [CytOx; mitochondria]). More details about these procedures have been published elsewhere (see [24,25] and the references cited therein).

\subsection{Bacterial strains and MIC determinations}

The laboratory and clinical strains used in the present study are listed in Table 1 with information on their origins and resistance phenotypes. MICs were determined by microdilution in CA-MHB following the recommendations of the Clinical and Laboratory Standards Institute (CLSI) [26]. For afabicin desphosphono testing, we applied the recommendations of CLSI for compounds with limited water solubility, i.e. by preparing stock solutions in DMSO followed by dilution so that the final DMSO concentration was reduced to a constant value of $1 \%$ across the whole range of afabicin desphosphono concentrations investigated. For daptomycin, MICs were measured in the presence of $50 \mathrm{mg} / \mathrm{L} \mathrm{Ca}^{++}$[26].

\subsection{Pharmacodynamic studies}

Experiments were conducted essentially as described previously (see $[20,25]$ and the references cited therein) and performed in broth for extracellular bacteria and with infected cells for intracellular bacteria (antibiotics were added to the culture medium immediately after phagocytosis and removal of non-phagocytized bacteria, as per our standard protocol), using a wide range of antibiotic concentrations (typically $0.01-100 \mathrm{x}$ MIC) to obtain full concentration-effect relationships. Data were used to fit a sigmoidal function

$\mathrm{y}=\mathrm{E}_{\max }+\frac{\mathrm{E}_{\min }-\mathrm{E}_{\max }}{1+10^{\left(\left(\log \mathrm{EC}_{50}-\mathrm{x}\right) * \text { slope }\right)}}$

(4 coefficients Hill equation), where the dependent variable $\mathrm{y}$ is the change in the number of cfu (per $\mathrm{mL}$ of medium for extra- cellular bacteria or per mg of cell protein for intracellular bacteria) from the initial post-phagocytosis inoculum (in $\log _{10}$ units), the independent variable $\mathrm{x}$ is the antibiotic extracellular concentration (also in $\log _{10}$ units), and the 4 coefficients (parameters) $E_{\max }, E_{\min }, \mathrm{EC}_{\mathbf{5 0}}$, and slope are, respectively, (i) the maximal reduction of cfu from the original post-phagocytosis inoculum (in $\log _{10}$ units) as extrapolated for an infinitely large antibiotic concentration (denoting its maximal relative efficacy), (ii) the maximal increase in cfu from the original past-phagocytosis inoculum (in $\log _{10}$ units) as extrapolated for an infinitely low antibiotic concentration(denoting its minimal relative efficacy and corresponding to the maximal bacterial growth that could be observed in the absence of antibiotic), (iii) the antibiotic extracellular concentration giving a change in cfu (in $\log _{10}$ units) halfway between $\mathrm{E}_{\text {min }}$ and $\mathrm{E}_{\max }$, and (iv) the Hill factor describing the steepness of the curves (set always to 1 because (a) there is no theoretical reason nor experimental evidence of positive or negative cooperativity in the responses; (b) attempts to improve the fitting of the function to the data using lower or higher values resulted in divergences between drugs and strains that were without constant emerging trend and, therefore, considered meaningless). The use of logarithmic transformation for concentrations ( $x$ ) is in line with that commonly used to describe pharmacological dose-responses when doses span several orders of magnitude, as is the case here. The change in cfu (y) also needs to be treated logarithmically because chemotherapeutic responses, unlike enzyme inhibition or proportion of ligand bound to a receptor, for instance, progress by fractional and not constant changes upon finite increases in drug concentration. The fitted functions were used to calculate the parameter $C_{\boldsymbol{s}}$ (apparent static concentration, i.e. the antibiotic total concentration [in broth or in the cell culture medium] that caused no apparent change in the number of cfu (per mL [broth] or per mg cell protein [THP-1 monocytes]) at the end of the experiment) [20].

\subsection{Afabicin desphosphono stability studies}

The stability of afabicin desphosphono was assessed by measuring its concentration during and at the end of the experiments using a validated liquid-chromatography-tandem mass spectrometry assay (LC-MS-MS; performed by Atlanbio, Saint-Nazaire, France 


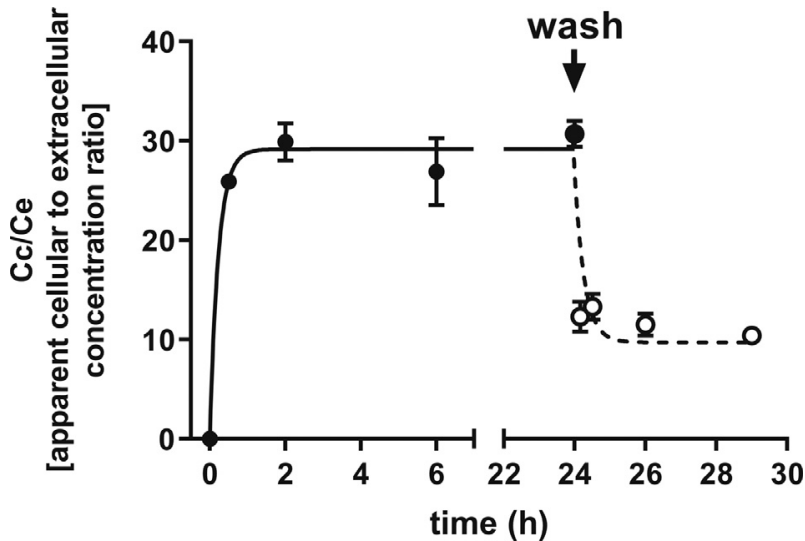

Fig. 2. Accumulation (closed symbols; solid line) and release (open symbols; dotted line) of afabicin desphosphono (Debio 1452) into and out of J774 macrophages. Accumulation: cells were incubated with $1.4 \mathrm{mg} / \mathrm{L}\left[{ }^{14} \mathrm{C}\right]$-Debio 1452 for up to $24 \mathrm{~h}$ and collected. Release: after incubation for $24 \mathrm{~h}$ in the presence of $1.4 \mathrm{mg} / \mathrm{L}\left[{ }^{14} \mathrm{C}\right]-$ Debio 1452, cells were quickly washed in situ with PBS (wash) and reincubated in drug-free medium for up to $6 \mathrm{~h}$ and collected. Cell-associated drug contents were measured by scintillation counting, expressed in $\mathrm{mg} / \mathrm{L}$ (based on a cell volume of $5 \mu \mathrm{L} / \mathrm{mg}$ protein) and compared to the extracellular concentration to calculate the apparent cellular-to-extracellular concentration ratio. Data $(n=4$ for each experimental point) were used for fitting a one-phase association (for accumulation) and a one-phase decay (for release) to estimate the respective rate constants ( $k_{\text {in }}=4.38$ $\left.\mathrm{h}^{-1} ; k_{\text {out }}=3.60 \mathrm{~h}^{-\mathbf{1}}\right)$, half-lives $(0.15$ and $0.19 \mathrm{~h})$ and plateaus $(29.2$ and 10.4$)$.

under contract with Debiopharm). Nominal mean deviations from known values in the 75 to $750 \mathrm{ng} / \mathrm{mL}$ calibration range were 32.8 $\pm 5.2 \%$ (standard error of the mean [SEM]; $\mathrm{n}=45$ ).

\subsection{Curve fitting, calculations, and statistical analyses}

Curve fitting (non-linear regression and calculation of the $\mathrm{E}_{\max }$ and $E_{\min }$ function parameters with their standard deviations and confidence intervals [Cls]) was performed with GraphPad Prism (versions 4.03 and 8.2.0) and statistical analyses of the differences with GraphPad InStat (version 3.10) software (GraphPad Software Inc., San Diego, CA). Calculation of the mean $C_{s}$ parameter (apparent static concentrations) and its CI was made with Excel 2013 (Microsoft Corporation, Redmond, WA) using the functions fitted to each set of replicates (usually 3) as determined by GraphPad.

\section{Results}

\subsection{Cellular pharmacokinetic studies}

\subsubsection{Uptake and efflux of $\left[{ }^{\mathbf{1 4}} \mathrm{C}\right]$-labelled afabicin desphosphono in uninfected 7774 macrophages}

Fig. 2 shows the accumulation of $\left[{ }^{14} \mathrm{C}\right]$-labelled afabicin desphosphono in J774 macrophages incubated with $1.4 \mathrm{mg} / \mathrm{L}$ $\left[{ }^{14} \mathrm{C}\right.$ ]-Debio 1452 for up to $24 \mathrm{~h}$. Uptake was very rapid, reaching a stable apparent content of about $21 \mu \mathrm{g} / \mathrm{mg}$ of protein, which corresponded to a cellular-to-extracellular concentration ratio of about 30 -fold within $2 \mathrm{~h}$ (assuming a cell volume to cell protein ratio of $5 \mu \mathrm{L} / \mathrm{mg}$ protein [21]). When cells were transferred to drug-free medium, about two-thirds of the afabicin desphosphono taken up by cells was released as quickly as it had accumulated, while the remaining third remained in an apparently stable fashion for at least $6 \mathrm{~h}$.

\subsubsection{Subcellular distribution of $\left[{ }^{\mathbf{1 4}} \mathrm{C}\right]$-labelled afabicin desphosphono in uninfected J774 macrophages and THP-1 monocytes}

J774 macrophages were exposed to $1 \mathrm{mg} / \mathrm{L}\left[{ }^{14} \mathrm{C}\right]$-labelled afabicin desphosphono for $1 \mathrm{~h}$ before being collected and subjected to controlled disruption, with the resulting homogenate sub-
Table 2

Recovery of radioactivity, marker enzymes and proteins in the cytoplasmic extract prepared from homogenized J774 macrophages incubated for $1 \mathrm{~h}$ with $1 \mathrm{mg} / \mathrm{L}\left[{ }^{14} \mathrm{C}\right]$ labelled afabicin desphosphono.

\begin{tabular}{lll}
\hline Constituent & $\%^{1}$ & SRA $^{2}$ \\
\hline afabicin desphosphono & 69.4 & 0.97 \\
cytochrome $c$-oxidase & 70.4 & 0.98 \\
N-acetyl- $\beta$-hexosaminidase & 66.0 & 0.92 \\
lactate dehydrogenase & 68.9 & 0.96 \\
proteins & 71.9 & \\
\hline $1 \%$ of the amount present in the original homogenate & \\
2 Specific Relative Activity (\% of each constituent /\% of protein) &
\end{tabular}

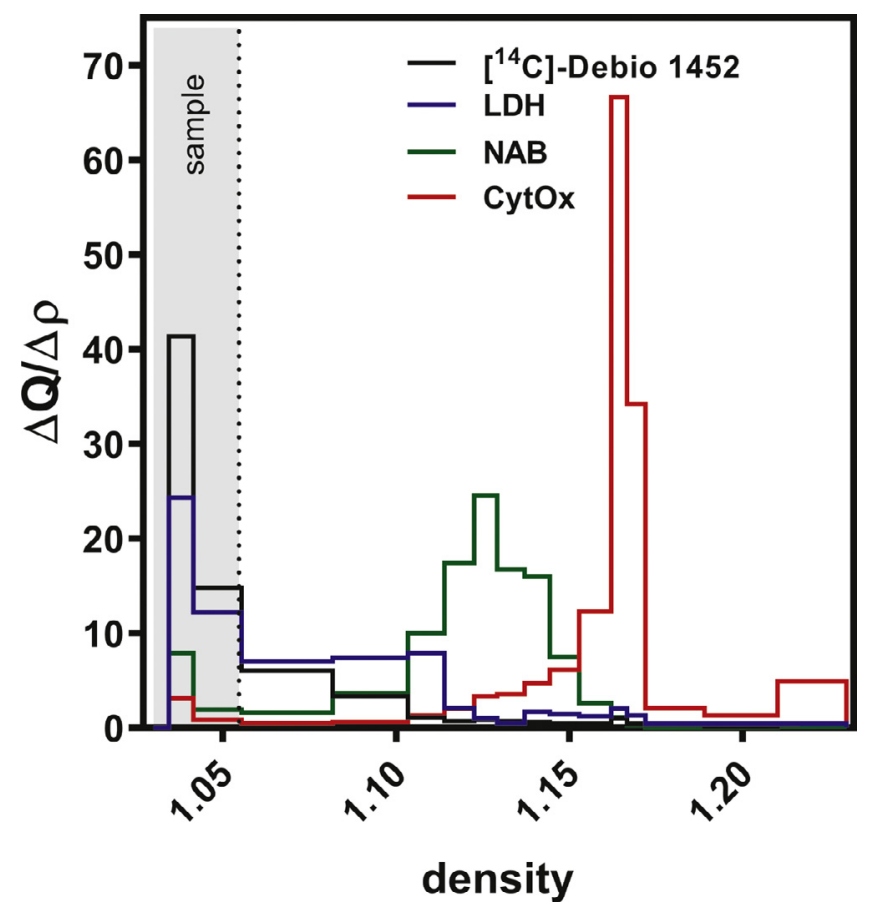

Fig. 3. Fractionation of a cytoplasmic extract of J774 macrophages by isopycnic centrifugation in a linear sucrose gradient. Cells were incubated with $1 \mathrm{mg} / \mathrm{L}\left[{ }^{14} \mathrm{C}\right]-$ labelled afabicin desphosphono (Debio 1452) for $1 \mathrm{~h}$ prior to collection. Results are presented as histograms of density distribution of $\left[{ }^{14} \mathrm{C}\right]$ radioactivity and of the marker enzymes (lactate dehydrogenase (LDH; cytosol), cytochrome $c$-oxidase (CytOx; mitochondria), and $\mathrm{N}$-acetyl- $\beta$-hexosaminidase (NAB, lysosomes). The abscissa is the density span of the gradient (with lower and upper limits set arbitrarily at 1.03 and 1.23 , respectively [no material was collected below or above these limits]). The ordinate is the distribution frequency defined as the fractional amount of activity recovered in each fraction $(\Delta Q)$ divided by the density span $(\Delta \rho)$ of that fraction. The surface of each section of each diagram therefore represents the fraction of that constituent recovered in the corresponding fraction and the total area of each diagram is 1 (to enable direct comparison between constituents). The grey area (limited by the vertical dotted line) corresponds to the position of the sample initially deposited on top of the gradient. Data are from a single experiment that was repeated twice with very similar results.

jected to both differential and isopycnic centrifugation. Table 2 shows that about $70 \%$ of the cell-associated radioactivity could be collected in the cytoplasmic extract (obtained after removal of nuclei and unbroken cells [fraction $\mathrm{N}$ ]), with the same relative specific activity as marker enzymes of mitochondria (cytochrome $c$-oxidase), lysosomes ( $\mathrm{N}$-acetyl- $\beta$-hexosaminidase), or cytosol (lactate dehydrogenase), thereby ruling out any specific association of afabicin desphosphono to nuclei (almost all if not all collected in the $\mathrm{N}$ fraction, based on microscopic [phase contrast] examination). Fig. 3 shows that after subjecting this cytoplasmic extract to isopycnic centrifugation, $\left[{ }^{14} \mathrm{C}\right]$-labelled afabicin desphosphono was essentially re- 


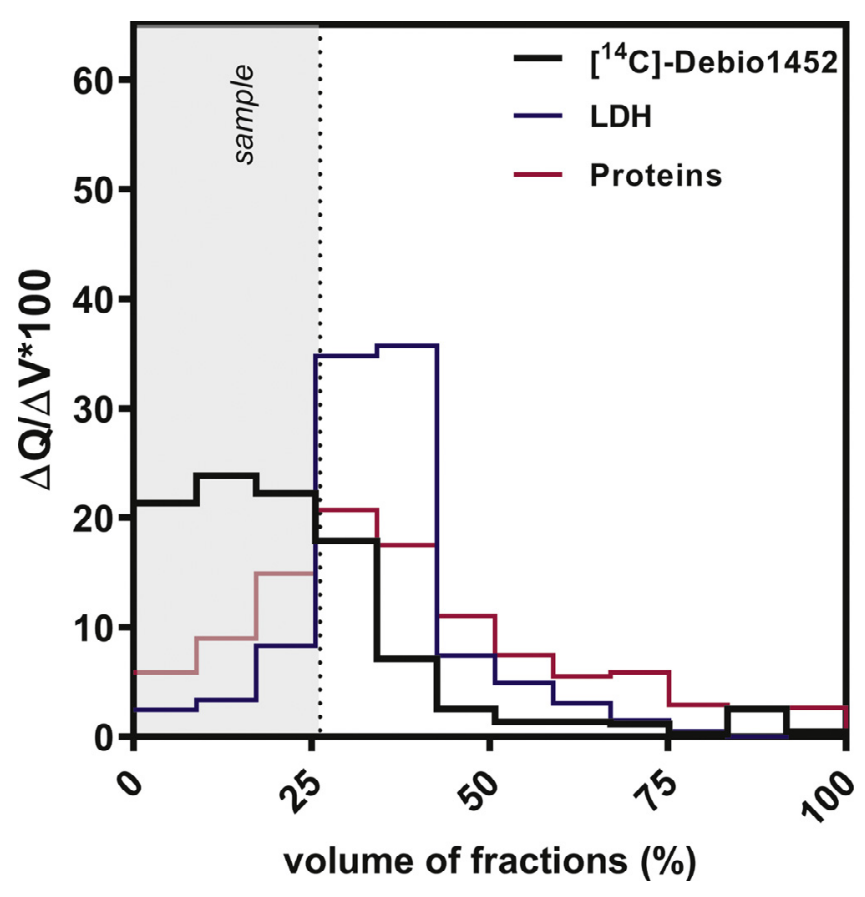

Fig. 4. 24-h high-speed (35 $000 \mathrm{rpm}$ ) centrifugation of a cell supernatant (fraction S) prepared from THP-1 monocytes incubated with $1 \mathrm{mg} / \mathrm{L}\left[{ }^{14} \mathrm{C}\right]$-labelled afabicin desphosphono (Debio 1452) for $1.5 \mathrm{~h}$ and deposited at the top of a sucrose gradient (density limits 1.10-1.24). Results are presented as histograms of volume distribution of $\left[{ }^{14} \mathrm{C}\right]$ radioactivity, lactate dehydrogenase (LDH; a soluble protein), and total proteins. The abscissa is the cumulated volume of the fractions (in \% of the total volume). The ordinate is the distribution frequency defined as the percent amount of activity or protein recovered in each fraction $(\Delta \mathrm{Q})$ divided by the fractional volume $(\Delta \mathrm{V})$ of that fraction. The surface of each section of each diagram therefore represents the fraction of activity or protein recovered in the corresponding fraction and the total area of each diagram is 100 (to enable direct comparison between constituents). The grey area (limited by the vertical dotted line) corresponds to the position of the sample initially deposited on top of the gradient.

covered in the first two fractions, corresponding to the initial sample, with minimal amounts associated with fractions of higher density. Lactate dehydrogenase (a soluble protein) was also recovered mainly in the top two fractions; however, a small but sizeable fraction was also recovered in denser fractions, indicating partial binding or adsorption to structures migrating into the gradient. This was not observed for $\left[{ }^{\mathbf{1 4}} \mathrm{C}\right]$-labelled afabicin desphosphono, which indicates that the drug was essentially soluble. Complete dissociation was obtained from $\mathrm{N}$-acetyl- $\beta$-hexosaminidase (lysosomes) and cytochrome $c$-oxidase (mitochondria). A fractionation of control cells (no afabicin desphosphono added) performed in parallel showed similar distributions for the 3 marker enzymes (data not shown), indicating no major effect of afabicin desphosphono on the properties of the corresponding subcellular entities.

Differential centrifugation studies with THP-1 monocytes showed that the bulk of the accumulated $\left[{ }^{14} \mathrm{C}\right]$-labelled afabicin desphosphono was collected in the $\mathrm{S}$ fraction (soluble material). No attempt was made to subject the fraction E (cytoplasmic extract) of THP-1 monocytes to isopycnic centrifugation because of known poor separation of mitochondria and lysosomes in these cells. To confirm that the predominant recovery of cell-associated afabicin desphosphono in the $\mathrm{S}$ fraction corresponded to truly soluble (free) molecule, an experiment was designed in which an $\mathrm{S}$ fraction prepared from THP-1 monocytes incubated with $2 \mathrm{mg} / \mathrm{L}\left[{ }^{14} \mathrm{C}\right]$-labelled afabicin desphosphono (90 $\mathrm{min}$ ) was deposited on top of a sucrose gradient and subjected to long-term, high-speed centrifugation (enabling partial migration of large molecular weight proteins). Fig. 4 shows that $\left[{ }^{14} \mathrm{C}\right]$-labelled afabicin desphosphono was

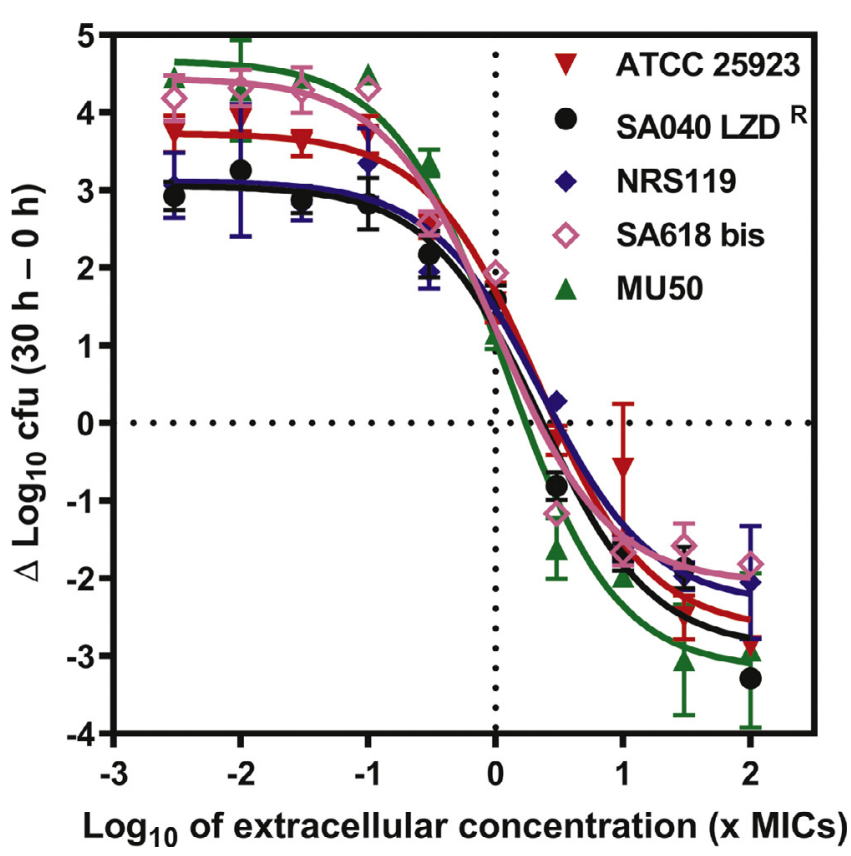

Fig. 5. Concentration-response curves of afabicin desphosphono against extracellular forms (broth) of $S$. aureus strains with different resistance phenotypes (see Table 1 ). The ordinate shows the change in the number of cfu from the initial inoculum (per $\mathrm{mL}$ ) after $30 \mathrm{~h}$ of incubation. The abscissa shows the extracellular concentrations expressed as multiples of MIC for the corresponding strain (see Table 1). The horizontal dotted line corresponds to the initial inoculum and enables calculation of the apparent static effect $\left(C_{s}\right)$ of each antibiotic. The data were used to fit Hill equations (slope factor $=1$ ). All data are means \pm SEM (triplicate experiments with each assay performed in triplicate).

again essentially recovered in the top fractions (accounting for $65.2 \%$ of the original sample) and was now largely dissociated from lactate-dehydrogenase and total proteins.

\subsection{Microbiological, pharmacodynamic and stability studies}

\subsubsection{Susceptibility of S. aureus strains of various resistance} phenotypes to afabicin desphosphono and comparator antibiotics

Table 1 shows the MICs for afabicin desphosphono and comparator antibiotics (oxacillin, clarithromycin, vancomycin, daptomycin, linezolid, and moxifloxacin) against the laboratory and clinical strains of $S$. aureus used in this study. Afabicin desphosphono consistently showed a very low MIC (0.0039 to $0.0019 \mathrm{mg} / \mathrm{L})$, which was well within the proposed quality control range with S. aureus ATCC 29213 reported in an earlier study [27].

\subsubsection{Pharmacodynamics of afabicin desphosphono against the} extracellular forms of $\mathrm{S}$. aureus strains of various resistance phenotypes

Five $S$. aureus strains were used to explore the concentrationeffect relationship of afabicin desphosphono when tested over a wide range of concentrations (0.003-100x MIC) for $30 \mathrm{~h}$ in broth (as our previous studies used a standard $24 \mathrm{~h}$ incubation time $[20,28]$, we checked with the comparators [historical controls] that prolonging the incubation time to $30 \mathrm{~h}$ did not significantly change their maximal relative efficacy or potency). Fig. 5 shows that a Hill function with slope factor set to 1 could be fitted to the data of all strains, with minimal relative efficacies $\left(\mathrm{E}_{\mathbf{m i n}}\right)$ of +3.1 (strain SA040 LZD $^{\mathbf{R}}$ ) to +4.6 (strain MU50) and maximal relative efficacies $\left(E_{\max }\right.$ ) of -2.3 (strain NRS119) to -3.2 (strain MU50) $\log _{10}$ cfu compared with the initial inocula, and apparent static concentrations $\left(C_{s}\right)$ ranging from 1.6-fold (strain MU50) to 3.0-fold (strain NRS119) of the corresponding MICs. 
3.2.3. Pharmacodynamics of afabicin desphosphono and comparator antibiotics against intracellular forms of $\mathrm{S}$. aureus of various resistance phenotypes

Afabicin desphosphono and 3 comparators (vancomycin, daptomycin and linezolid) were used to explore concentration-effect relationships towards the intracellular forms of the fully susceptible ATCC 25923 laboratory strain and towards 3 selected isolates resistant to one or two of the comparators. Fig. 6 illustrates the results obtained after $30 \mathrm{~h}$ of incubation (as for our studies of the extracellular forms, the longer incubation time compared with our previous studies did not significantly change the maximal relative efficacy or potency of the comparators [historical controls]), and the corresponding key pharmacodynamic parameters and statistical analysis of the differences are listed in Table 3. A typical sigmoidal concentration-response (Hill function with slope factor set to 1) could be fitted for all strains and all antibiotics as for the extracellular bacteria. $\mathrm{E}_{\min }$ values (corresponding essentially to the intracellular bacterial growth in the absence of antibiotic) were between +2.8 (strain NRS119) and +4.2 (strain SA040 LZD ${ }^{\mathbf{R}}$ ) $\log _{10} \mathrm{cfu}$, (i.e., close to $\mathrm{E}_{\min }$ values for extracellular bacteria). As previously described in this model, $E_{\max }$ values (maximal relative efficacies) of afabicin desphosphono and all comparators were lower (less negative) for intracellular bacteria than for extracellular bacteria (with values spanning from 0.56 to only $-0.73 \log _{10}$ cfu; no significant difference between antibiotics). Conspicuously, the apparent intracellular static concentration $\left(C_{s}\right)$ for each antibiotic and each strain was only slightly higher (1.5- to 7-fold) than the corresponding MICs as determined in broth, with no or only small differences across all data.

The last series of experiments examined whether afabicin desphosphono would retain its intracellular activity if added to infected cells $8 \mathrm{~h}$ after phagocytosis and removal of the nonphagocytized bacteria. Fig. 7 shows there was no meaningful difference between cells treated according to this protocol and those for which afabicin desphosphono had been added immediately after phagocytosis and removal of the non-phagocytized bacteria.

\subsubsection{Stability of afabicin desphosphono in media of infected THP-1 monocytes}

To ascertain that afabicin desphosphono was not degraded in the conditions in which it was used to study its intracellular activity, media from infected THP-1 monocytes exposed to afabicin desphosphono at 3 different concentrations (75, 225 and $750 \mathrm{mg} / \mathrm{L}$ [about 20, 40 and 200x the MIC, respectively]) for $30 \mathrm{~h}$ were collected after $6,12,24$ and $30 \mathrm{~h}$ of incubation and the afabicin desphosphono content compared to that of non-incubated samples $(0 \mathrm{~h})$ using an LC-MS-MS assay. Mean recovery of afabicin desphosphono at 30 h was still $76.3 \%$ (95\%CI: 71.3 to $81.8 ; n=9$ ) compared with the mean values observed at $0 \mathrm{~h}(P=0.014$ [unpaired t-test; two-tailed]).

\section{Discussion}

The present study is the first to describe the in vitro cellular pharmacokinetics and disposition of afabicin desphosphono (and, as far as we know, any FabI inhibitor) in murine and human phagocytic cells and to assess its intracellular activity against phagocytized $S$. aureus in a validated pharmacodynamic model of human monocytes.

This study shows that afabicin desphosphono accumulates quickly and markedly in cultured murine macrophages and is released as quickly, although only partially, upon drug removal. Cellassociated afabicin desphosphono is essentially recovered with the soluble cell fraction, with no evidence of significant association with subcellular organelles, and in a form that is unlikely to be
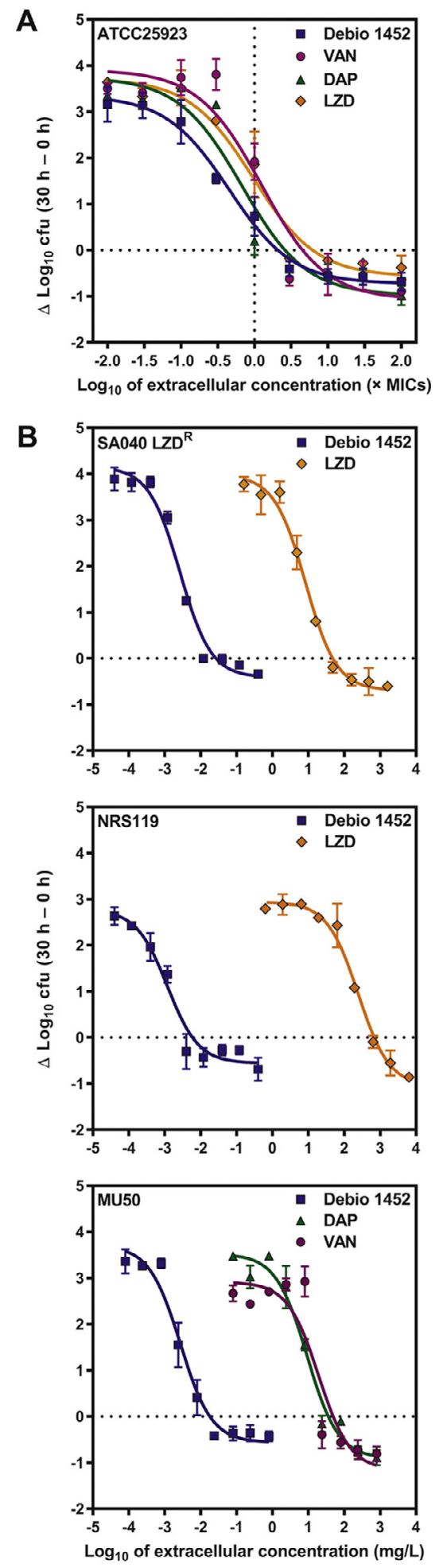

Fig. 6. Concentration-response curves of afabicin desphosphono (Debio 1452), vancomycin (VAN), daptomycin (DAP) and linezolid (LZD) intracellular forms of S. aureus strains with different resistance phenotypes (see Table 1). The ordinate of all graphs shows the change in the number of cfu from the initial inoculum per $\mathrm{mg}$ of cell protein in THP-1 monocytes after $30 \mathrm{~h}$ of incubation. The abscissa shows the extracellular concentrations expressed as follows: A (ATCC25923 [categorized as susceptible to VAN, DAP and LZD]) in multiples of MIC for the corresponding antibiotic (the vertical dotted line corresponds to the MIC); B (all other strains): in $\mathrm{mg} / \mathrm{L}$ (to illustrate the difference in susceptibility between afabicin desphosphono and the comparator antibiotic(s) to which the strains is reported to be resistant). The horizontal dotted line in each graph corresponds to the initial inoculum and enables calculation of the apparent static effect $\left(C_{s}\right)$ of each antibiotic. The data were used to fit Hill equations (slope factor $=1$ ). All data are means \pm SEM (triplicate experiments for afabicin desphosphono and duplicate experiments for the other antibiotics, with each assay performed in triplicate). 
Table 3

Pharmacological parameters and statistical analysis of the dose-response curves of antibiotics against all strains tested in THP-1 monocytes

\begin{tabular}{|c|c|c|c|c|c|}
\hline \multirow{2}{*}{$\begin{array}{l}25923 \\
\text { Antibiotic and strain }\end{array}$} & \multirow[b]{2}{*}{$\mathrm{E}_{\min }^{\mathrm{a}, \mathrm{d}}$} & \multirow[b]{2}{*}{$\mathrm{E}_{\max } \mathrm{b,d}$} & \multicolumn{2}{|l|}{$\mathrm{C}_{\mathrm{s}}^{\mathrm{c}, \mathrm{d}}$} & \multirow[t]{2}{*}{$\mathrm{R}^{2}$} \\
\hline & & & $\mathrm{mg} / \mathrm{L}$ & $\mathrm{X}$ MIC & \\
\hline \multicolumn{6}{|c|}{ Afabicin desphosphono } \\
\hline ATCC25923 & 3.35 (2.93 to 3.77$) \mathrm{A} ; \mathrm{a}$ & $-0.73(-1.04$ to -0.41$) \mathrm{A} ; \mathrm{a}$ & 0.009 (0.001 to 0.117$) \mathrm{A}: \mathrm{a}$ & 2.27 (0.58 to 4.21$) \mathrm{A} ; \mathrm{a}$ & 0.92 \\
\hline SA040 LZD ${ }^{\mathrm{R}}$ & 4.15 (3.89 to 4.42$) \mathrm{A} ; \mathrm{c}$ & $-0.41(-0.64$ to -0.18$) \mathrm{A} ; \mathrm{a}$ & $0.027(0.012$ to 0.092$) \mathrm{A} ; \mathrm{a}$ & 6.97 (2.97 to 23.5$) \mathrm{A} ; \mathrm{a}, \mathrm{b}$ & 0.97 \\
\hline NRS119 & 2.77 (2.39 to 3.16$) \mathrm{A} ; \mathrm{b}$ & $-0.56(-0.80$ to -0.31$) \mathrm{A} ; \mathrm{a}$ & $0.006(0.002$ to 0.022$) \mathrm{A} ; \mathrm{a}$ & 1.53 (0.51 to 5.58$) \mathrm{A} ; \mathrm{a}, \mathrm{c}$ & 0.93 \\
\hline MU50 & 3.70 (3.26 to 4.15$)$ A;a,c & $-0.56(-0.87$ to -0.26$) \mathrm{A} ; \mathrm{a}$ & $0.018(0.006$ to 0.074$) \mathrm{A} ; \mathrm{a}$ & 4.63 (1.54 to 18.9$) \mathrm{A} ; \mathrm{a}$ & 0.94 \\
\hline \multicolumn{6}{|c|}{ Pooled data (parameters calculated using one single regression for all strains) } \\
\hline & $3.47(3.22$ to 3.73$)$ & $-0.56(-0.75$ to -0.36$)$ & $0.011(0.005$ to 0.024$)$ & $2.76(1.36$ to 6.32$)$ & 0.88 \\
\hline \multicolumn{6}{|l|}{ Linezolid } \\
\hline ATCC25923 & $3.72(3.27$ to 4.16$) \mathrm{A} ; \mathrm{a}$ & $-0.57(-1.01$ to -0.13$) \mathrm{A} ; \mathrm{a}$ & 24.8 (6.63 to 226$) \mathrm{B} ; \mathrm{a}$ & $6.21(1.66$ to 56.5$) \mathrm{A} ; \mathrm{a}$ & 0.98 \\
\hline SA040 LZD ${ }^{\mathrm{R}}$ & 3.97 (3.61 to 4.33 ) $\mathrm{A} ; \mathrm{a}, \mathrm{b}$ & $-0.69(-0.98$ to 0.40$) \mathrm{A} ; \mathrm{a}$ & 48.0 (20.3 to 136$) \mathrm{B} ; \mathrm{a}$ & $3.00(1.27$ to 8.51$) \mathrm{A} ; \mathrm{a}$ & 0.96 \\
\hline NRS119 & $2.94(2.72$ to 3.16$) \mathrm{A} ; \mathrm{c}$ & $-1.06(-1.42$ to -0.69$) \mathrm{B} ; \mathrm{a}$ & 683 (303 to 1748 ) B;b & 5.34 (2.37 to 13.7$) \mathrm{B} ; \mathrm{a}$ & 0.95 \\
\hline \multicolumn{6}{|l|}{ Daptomycin } \\
\hline ATCC25923 & 3.75 (3.19 to 4.30$) \mathrm{A} ; \mathrm{a}$ & $-0.97(-1.46$ to -0.49$) \mathrm{A} ; \mathrm{a}$ & 2.61 (0.76 to11.7) B;a & $2.61(0.76$ to 11.7$) \mathrm{A} ; \mathrm{a}$ & 0.96 \\
\hline MU50 & 3.52 (3.16 to 3.88 ) A,B;a & $-0.90(-1.28$ to -0.53$) \mathrm{A} ; \mathrm{a}$ & 36.0 (13.8 to 112 ) $\mathrm{B} ; \mathrm{b}$ & $4.50(1.73$ to 14.5$) \mathrm{A} ; \mathrm{a}$ & 0.96 \\
\hline ATCC25923 & 3.90 (3.30 to 4.51$) \mathrm{A} ; \mathrm{a}$ & $-1.08(-1.74$ to -0.41$) \mathrm{A} ; \mathrm{a}$ & 4.53 (1.09 to 29.8 ) B;a & 4.53 (1.09 to 29.8$) \mathrm{A} ; \mathrm{a}$ & 0.97 \\
\hline MU50 & 2.91 (2.33 to 3.50$) \mathrm{B} ; \mathrm{b}$ & $-1.15(-1.96$ to -0.34$) \mathrm{A} ; \mathrm{a}$ & 49.2 (8.34 to 549 ) $\mathrm{B} ; \mathrm{a}$ & 6.15 (1.04 to 68.7$) \mathrm{A} ; \mathrm{a}$ & 0.95 \\
\hline
\end{tabular}

${ }^{a}$ CFU increase (in $\log _{10}$ units, with confidence interval) at $24 \mathrm{~h}$ from the corresponding initial inoculum as extrapolated from the Hill equation of the concentration-effect response for an infinitely low antibiotic concentration.

b CFU decrease (in $\log _{10}$ units, with confidence interval) at $24 \mathrm{~h}$ from the corresponding initial inoculum as extrapolated from the Hill equation of the concentration-effect response for an infinitely large antibiotic concentration.

${ }^{c}$ extracellular antibiotic concentration (with confidence intervals) resulting in no apparent bacterial growth as calculated from the Hill equation of the concentration-response curve.

d Statistical analyses: one-way analysis of variance with Tukey-Kramer multiple-comparison $t$ test. Values with different upper case letters denote a statistically significant difference for the same strain in cells exposed to different antibiotics (thus, for instance, for $\mathrm{E}_{\mathbf{m a x}}$ of strain NRS119 in cells exposed to afabicin desphosphono vs. linezolid [marked A and B, respectively), whereas values with different lower case letters denote statistically significant differences between different strains in cells exposed to the same antibiotic For instance, for $C_{\mathbf{s}}$ (in $\mathrm{mg} / \mathrm{L}$ ) of strain ATCC25923 vs. strain NRS119 in cells exposed to linezolid (marked a and b, respectively). For $C_{s}$ values that show an asymmetrical confidence interval, statistical analysis used the log transformed data.

bound to proteins or other soluble macromolecules. This behaviour is largely reminiscent of that observed with fluoroquinolones [18] (see also review in [29]) as well as the oxazolidinone, tedizolid [30] and the deformylase inhibitor, GSK1322322 [24]. It differs markedly from that reported for macrolides, the dibasic biaryloxazolidinone radezolid, or the novel triazaacenaphthylene bacterial topoisomerase inhibitor gepotidacin (GSK2140944), all of which accumulate rapidly in cells but become largely associated with lysosomes $[17,19,25]$, probably because of proton-trapping [31]. Afabicin desphosphono may diffuse rapidly through the pericellular membrane, consistent with its non-ionized character and a positive $\log \mathrm{D}$ value (3.01) at $\mathrm{pH} 7.4$ (two properties shared by tedizolid and GSK1322322, based on biophysical properties calculations [Chemaxon, Budapest, Hungary; https://chemaxon.com/]) and binds reversibly and loosely to still unidentified cellular constituents. Such loose binding, however, is likely to be defeated upon dilution, such as that occuring during the cell fractionation studies, which would explain why the drug is found essentially soluble when applying this technique. If this is the case, the accumulated drug may be able to access various subcellular organelles, such as phagolysosomes. Interestingly, recent studies performed in humans showed an accumulation of afabicin desphosphono in cortical, cancellous, bone marrow and soft tissue and synovial fluid of patients who received the prodrug form, indicating it could act in these niches [13]. Accumulation of afabicin desphosphono into macrophages may also enable increased concentrations at infection sites due to recruitment of leukocytes upon infection and inflammation. Indeed, penetration of afabicin desphosphono in bone tissues of animal models was increased when these were infected [32].

Access to intracellular targets and expression of activity therein was assessed directly in our pharmacodynamic model. Considering extracellular bacteria, this study confirms that afabicin desphosphono has unhindered antibacterial activity against laboratory and clinical S. aureus strains, irrespective of their resistance to other

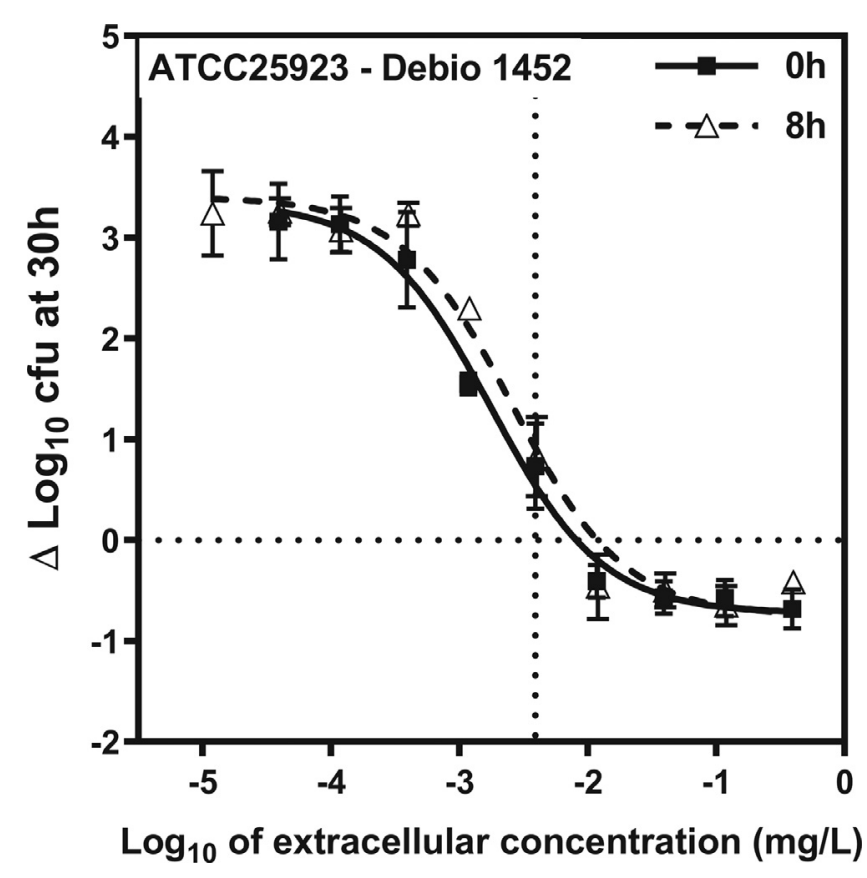

Fig. 7. Concentration-response curves of afabicin desphosphono (Debio 1452) against the intracellular forms of $S$. aureus ATCC25923 in THP-1 monocytes exposed to antibiotics immediately after phagocytosis and removal of the non-phagocytized bacteria ( $0 \mathrm{~h}$; closed squares and solid line) or added after $8 \mathrm{~h}$ of culture of the infected cells in an antibiotic-free medium ( $8 \mathrm{~h}$, open triangles; dotted line). The ordinate shows the change in the number of cfu from the initial inoculum per mg of cell protein in THP- 1 monocytes after $30 \mathrm{~h}$ of incubation with the antibiotic. The abscissa shows the extracellular concentrations (in $\mathrm{mg} / \mathrm{L}$ ). The horizontal and vertical dotted lines correspond to the initial inoculum and to the MIC of afabicin desphosphono, respectively. The data were used to fit Hill equations (slope factor $=1$ ). All data are means \pm SEM (triplicate experiments). 
commonly recommended antistaphylococcal drugs, which is consistent with previous observations [33] and with its specific and distinct mode of action compared with other antibiotics [34]. With regard to intracellular activity, afabicin desphosphono is bacteriostatic against $S$. aureus phagocytized and thriving in human THP-1 monocytes, including strains resistant to other antistaphylococcal antibiotics, with very low $C_{s}$ values $(0.01$ to $0.03 \mathrm{mg} / \mathrm{L})$, which is in agreement with its good intracellular penetration. Similar to most antibiotic classes, there was a marked reduction in maximal efficacy of afabicin desphosphono towards intracellular bacteria (with mean $E_{\max }$ values never exceeding a $1.1 \log _{10}$ cfu decrease) compared with extracellular bacteria. Of note, $\mathrm{E}_{\max }$ is the extrapolated value for an infinitely large extracellular antibiotic concentration, which rules out that its low (less negative) value is related to impairment of penetration into bacteria (pharmacokinetic effect). Instead it indicates a lack of response of the bacteria to the antibiotic action (pharmacodynamic effect). This behaviour was also seen in this study with vancomycin and daptomycin, two antibiotics that have previously been shown to be markedly bactericidal towards extracellular bacteria $[25,35,36]$. Likewise, other bactericidal antibiotics from different pharmacological classes, such as gepotidacin [25], GSK1322322 [24], ceftaroline [36] and ceftobiprole [37], were shown to be only bacteriostatic against intracellular $S$. aureus in the same model, indicating a global alteration of the bacterial response to antibiotics when sojourning in THP-1 monocytes and disproving a pharmacokinetic or an antibiotic-specific pharmacodynamic effect. Two classes of antibiotics (fluoroquinolones and lipoglycopeptides, with moxifloxacin and oritavancin as typical examples, respectively), however, can have an intracellular bactericidal effect in our model [28], indicating that modulation of the bacterial response is possible, perhaps in relation to the target of the antibiotic under study. It is not known whether this difference in global effects will translate into clinically-demonstrable advantage(s). Plasma concentration at steady state has been presented for the intended therapeutic dosing regimen of $240 \mathrm{mg}$ oral BID [13]. Mean $C_{\max }$ was $2.4 \mathrm{mg} / \mathrm{L}$ and $C_{\text {trough }} 1.2 \mathrm{mg} / \mathrm{L}$. These concentrations far exceed the MICs ( 0.0019 to $0.0039 \mathrm{mg} / \mathrm{L}$ [Table 1]) and the extracellular concentrations yielding an intracellular bacteriostatic effect ( 0.009 to $0.027 \mathrm{mg} / \mathrm{L}$ [ $\mathrm{C}_{\mathbf{s}}$ parameter]; see Table 2$)$ even considering that afabicin desphosphono can be up to $98 \%$ proteinbound in human serum. Therefore, afabicin desphosphono could be as effective as the comparators (vancomycin, linezolid, and daptomycin) for controlling the multiplication of intracellular $S$. aureus in vivo.

The present study has limitations that need to be carefully considered. First, the model uses cells that show only very limited defences to infection (see discussion in [20] and the references cited therein). This limitation is by design to provide a simple pharmacological description of the intracellular effects of the antibiotics, but this design ignores how these cell defence mechanisms could improve or hinder the activity of afabicin desphosphono against intracellular $S$. aureus in vivo. Second, afabicin desphosphono is reported to show a marked protein binding ( $98 \%)$ in human serum, associated with an 8-fold increase in its MIC [38]. The impact of protein binding could not be assessed in the present study model because the serum concentration in the culture medium is low and cannot be varied to the extent required to assess its role on antibiotic intracellular activity. Third, future studies are needed to understand the mechanism(s) of accumulation of afabicin desphosphono in cells (and the reasons for its incomplete release) to establish whether and how the drug redistributes in cells upon homogenization and fractionation, and, most urgently, to find out why bacteria fail to be killed as efficiently in cells compared to in broth. Lastly, we focused our attention on a single time point to be in line with our approach to accurately measure and report pharmacological descriptors of activity, as done previously for many other an- tibiotics (see e.g. [24,25,28,35-37,39]). Establishing the intracellular pharmacokinetic/pharmacodynamic profile of afabicin desphosphono, including the influence of time on its activity, using dose fractionation studies would require development of an appropriate model and detailed knowledge of the complete human pharmacokinetic profile of afabicin in infected patients to be clinically relevant.

Despite these limitations, the present study shows clearly that afabicin desphosphono is accumulated by macrophages and exerts a bacteriostatic effect against $S$. aureus phagocytized by THP-1 monocytes. Expanding these studies to pertinent in vivo models of intracellular infection is warranted.

\section{Acknowledgements}

We thank Atlanbio for performing LC-MS-MS analysis of the samples used to assess the stability of afabicin desphosphono in our experimental conditions, and V. Yfantis for expert technical help.

\section{Declarations}

Funding: This was supported in part by a grant from Debiopharm International and by the Belgian Fonds National de la Recherche Scientifique (FNRS-FRS; grants T.0189.16 and J.0018.17). FP is an employee of the Université catholique de Louvain and GD, of Debiopharm International. AVW was a graduating student and PMT is an emeritus professor, both unpaid. FVB is Research Director of the Fonds de la Recherche Scientifique (F.R.S.-FNRS).

Competing interests: PMT and FVB have received grants and speakers honoraria from various companies involved in the discovery and development of drugs accumulating in cells and/or acting on intracellular bacteria.

\section{Ethical Approval: Not required}

\section{References}

[1] Reddy PN, Srirama K, Dirisala VR. An update on clinical burden, diagnostic tools, and therapeutic options of Staphylococcus aureus. Infect Dis (Auckl) 2017; 101179916117703999 - PM28579798.

[2] Tacconelli E, Magrini N. Global priority list of antibiotic-resistant bacteria to guide research, discovery, and development of new antibiotics. http://www. who.int/medicines/publications/global-priority-list-antibiotic-resistantbacteria/en/. Last updated: 27-2-2017 - last accessed: 3-2-2019

[3] Foster TJ. Antibiotic resistance in Staphylococcus aureus. Current status and future prospects. FEMS Microbiol Rev 2017;41:430-49 PM:28419231.

[4] Howden BP, Davies JK, Johnson PDR, Stinear TP, Grayson ML. Reduced vancomycin susceptibility in Staphylococcus aureus, including vancomycin-intermediate and heterogeneous vancomycin-intermediate strains: resistance mechanisms, laboratory detection, and clinical implications. Clin Microbiol Rev 2010;23:99-139 PM:20065327.

[5] Hashemian SMR, Farhadi T, Ganjparvar M. Linezolid: a review of its properties, function, and use in critical care. Drug Des Devel Ther 2018;12:1759-67 PM:29950810.

[6] Loffler B, Tuchscherr L, Niemann S, Peters G. Staphylococcus aureus persistence in non-professional phagocytes. Int J Med Microbiol 2014;304:170-6 PM:24365645.

[7] Kamaruzzaman NF, Kendall S, Good L. Targeting the hard to reach: challenges and novel strategies in the treatment of intracellular bacterial infections. $\mathrm{Br}$ Pharmacol 2017;174:2225-36 PM:27925153.

[8] Horn J, Stelzner K, Rudel T, Fraunholz M. Inside job: Staphylococcus aureus host-pathogen interactions. Int J Med Microbiol 2018;308:607-24 PM:29217333.

[9] Thomsen IP, Liu GY. Targeting fundamental pathways to disrupt Staphylococcus aureus survival: clinical implications of recent discoveries. JCI Insight 2018;3:10 PM:29515041.

[10] Karlowsky JA, Laing NM, Baudry T, Kaplan N, Vaughan D, Hoban DJ, et al. In vitro activity of API-1252, a novel FabI inhibitor, against clinical isolates of Staphylococcus aureus and Staphylococcus epidermidis. Antimicrob Agents Chemother 2007;51:1580-1 PM:17220418.

[11] Karlowsky JA, Kaplan N, Hafkin B, Hoban DJ, Zhanel GG. AFN-1252, a FabI inhibitor, demonstrates a Staphylococcus-specific spectrum of activity. Antimicrob Agents Chemother 2009;53:3544-8 PM:19487444. 
[12] Krishnamurthy NR, Lakshminarasimhan A, Subramanya HD. Aurigene Discovery Technologies Ltd, editor. Crystalline Structure of FABI from Burkholderia Pseudomallei. patent US 2017/0088822 A1. 2017 Mar 2017.

[13] Menetrey A, Janin A, Pullman J, Overcash JS, Haouala A, Leylavergne F, et al. Bone and joint tissues penetration of the Staphylococcus-selective antibiotic afabicin in patients undergoing elective hip replacement surgery. Antimicrob Agents Chemother 2019;63 pii:e01669-18 - PM:30559136.

[14] Kaplan N, Albert M, Awrey D, Bardouniotis E, Berman J, Clarke T, et al. Mode of action, in vitro activity, and in vivo efficacy of AFN-1252, a selective antistaphylococcal FabI inhibitor. Antimicrob Agents Chemother 2012;56:5865-74 PM:22948878

[15] Yao J, Carter RA, Vuagniaux G, Barbier M, Rosch JW, Rock CO. A pathogen-selective antibiotic minimizes disturbance to the microbiome. Antimicrob Agents Chemother 2016:60:4264-73 PM:27161626.

[16] Kaplan N, Garner C, Hafkin B. AFN-1252 in vitro absorption studies and pharmacokinetics following microdosing in healthy subjects. Eur J Pharm Sci 2013:50:440-6 PM:23988847.

[17] Carlier MB, Zenebergh A, Tulkens PM. Cellular uptake and subcellular distribution of roxithromycin and erythromycin in phagocytic cells. J Antimicrob Chemother 1987;20(Suppl B):47-56 PM:3429386.

[18] Carlier MB, Scorneaux B, Zenebergh A, Desnottes JF, Tulkens PM. Cellular uptake, localization and activity of fluoroquinolones in uninfected and infected macrophages. J Antimicrob Chemother 1990;26(Suppl B):27-39 PM: 2258352.

[19] Lemaire S, Tulkens PM, Van Bambeke F. Cellular pharmacokinetics of the novel biaryloxazolidinone radezolid in phagocytic cells: studies with macrophages and polymorphonuclear neutrophils. Antimicrob Agents Chemother 2010;54:2540-8 PM:20385873.

[20] Buyck J, Lemaire S, Seral C, Anantharajah A, Peyrusson F, Tulkens PM, et al. In vitro models for the study of the intracellular activity of antibiotics "Bacterial Persistence" (Molecular Biology Laboratory Protocols Series). Huamna Press (Springer); 2015.

[21] Renard C, Vanderhaeghe HJ, Claes PJ, Zenebergh A, Tulkens PM. Influence of conversion of penicillin $\mathrm{G}$ into a basic derivative on its accumulation and subcellular localization in cultured macrophages. Antimicrob Agents Chemother 1987;31:410-16 PM:3579258.

[22] Scorneaux B, Ouadrhiri Y, Anzalone G, Tulkens PM. Effect of recombinant human gamma interferon on intracellular activities of antibiotics against Listeria monocytogenes in the human macrophage cell line THP-1. Antimicrob Agents Chemother 1996;40:1225-30 PM:8723471.

[23] Seral C, Michot JM, Chanteux H, Mingeot-Leclercq MP, Tulkens PM, Van Bambeke $\mathrm{F}$. Influence of p-glycoprotein inhibitors on accumulation of macrolides in j774 murine macrophages. Antimicrob Agents Chemother 2003;47:1047-51 PM: 12604540.

[24] Peyrusson F, Butler D, Tulkens PM, Van Bambeke F. Cellular pharmacokinetics and intracellular activity of the novel peptide deformylase inhibitor GSK1322322 against Staphylococcus aureus laboratory and clinical strains with various resistance phenotypes: studies with human THP-1 monocytes and J774 murine macrophages. Antimicrob Agents Chemother 2015;59:5747-60 PM:26169402.

[25] Peyrusson F, Tulkens PM, Van Bambeke F. Cellular pharmacokinetics and intracellular activity of gepotidacin against Staphylococcus aureus isolates with different resistance phenotypes in models of cultured phagocytic cells. Antimicrob Agents Chemother 2018;62 e02245-17 - PM:29358297.
[26] Anonymous. Performance Standards for Antimicrobial Susceptibility Testing. In: 24th informational supplement (MS100-S24): Clinical and Laboratory Standard Institute, Wayne, PA; 2014

[27] Ross JE, Flamm RK, Jones RN. Initial broth microdilution quality control guidelines for Debio 1452, a FabI inhibitor antimicrobial agent. Antimicrob Agents Chemother 2015;59:7151-2 PM:26324261.

[28] Barcia-Macay M, Seral C, Mingeot-Leclercq MP, Tulkens PM, Van Bambeke F. Pharmacodynamic evaluation of the intracellular activities of antibiotics against Staphylococcus aureus in a model of THP- 1 macrophages. Antimicrob Agents Chemother 2006;50:841-51 PM:16495241.

[29] Tulkens PM. Intracellular distribution and activity of antibiotics. Eur J Clin Microbiol Infect Dis 1991;10:100-6 PM:1864271.

[30] Flanagan S, McKee EE, Das D, Tulkens PM, Hosako H, Fiedler-Kelly J, et al. Nonclinical and pharmacokinetic assessments to evaluate the potential of tedizolid and linezolid to affect mitochondrial function. Antimicrob Agents Chemother 2015;59:178-85 PM:25331703.

[31] de Duve C, de Barsy T, Poole B, Trouet A, Tulkens P, Van Hoof F. Commentary. Lysosomotropic agents. Biochem Pharmacol 1974;23:2495-531 PM:4606365.

[32] Barbier M, Menetrey A, Haouala A, Bravo J, Wittke F, Jacqueline C, Vuagniaux G. Efficacy of the FabI inhibitor afabicin for the treatment of Staphylococcus aureus-induced acute osteomyelitis in rabbit, abstr. In: 4495, ASM Microbe, Boston, MA, Washington, DC. American Society for Microbiology; 2016.

[33] Flamm RK, Rhomberg PR, Kaplan N, Jones RN, Farrell DJ. Activity of Debio1452, a FabI inhibitor with potent activity against Staphylococcus aureus and coagulase-negative Staphylococcus spp., including multidrug-resistant strains. Antimicrob Agents Chemother 2015;59:2583-7 PM:25691627.

[34] Banevicius MA, Kaplan N, Hafkin B, Nicolau DP. Pharmacokinetics, pharmacodynamics and efficacy of novel FabI inhibitor AFN-1252 against MSSA and MRSA in the murine thigh infection model. J Chemother 2013;25:26-31 PM:23433441.

[35] Barcia-Macay M, Lemaire S, Mingeot-Leclercq MP, Tulkens PM, Van Bambeke $\mathrm{F}$. Evaluation of the extracellular and intracellular activities (human THP-1 macrophages) of telavancin versus vancomycin against methicillin-susceptible, methicillin-resistant, vancomycin-intermediate and vancomycin-resistant Staphylococcus aureus. J Antimicrob Chemother 2006;58:1177-84 PM:17062609.

[36] Melard A, Garcia LG, Das D, Rozenberg R, Tulkens PM, Van Bambeke F, et al. Activity of ceftaroline against extracellular (broth) and intracellular (THP-1 monocytes) forms of methicillin-resistant Staphylococcus aureus: comparison with vancomycin, linezolid and daptomycin. J Antimicrob Chemother 2013;68:648-58 PM:23188792.

[37] Lemaire S, Glupczynski Y, Duval V, Joris B, Tulkens PM, Van Bambeke F. Activities of ceftobiprole and other cephalosporins against extracellular and intracellular (THP-1 macrophages and keratinocytes) forms of methicillin-susceptible and methicillin-resistant Staphylococcus aureus. Antimicrob Agents Chemother 2009;53:2289-97 PM:19289525.

[38] Kaplan N, Awrey D, Bardouniotis E, Berman J, Yethon J, Pauls HW, et al. In vitro activity (MICs and rate of kill) of AFN-1252, a novel FabI inhibitor, in the presence of serum and in combination with other antibiotics. J Chemother 2013;25:18-25 PM:23433440.

[39] Lemaire S, Van Bambeke F, Appelbaum PC, Tulkens PM. Cellular pharmacokinetics and intracellular activity of torezolid (TR-700): studies with human macrophage (THP-1) and endothelial (HUVEC) cell lines. J Antimicrob Chemother 2009;64:1035-43 PM:19759040. 